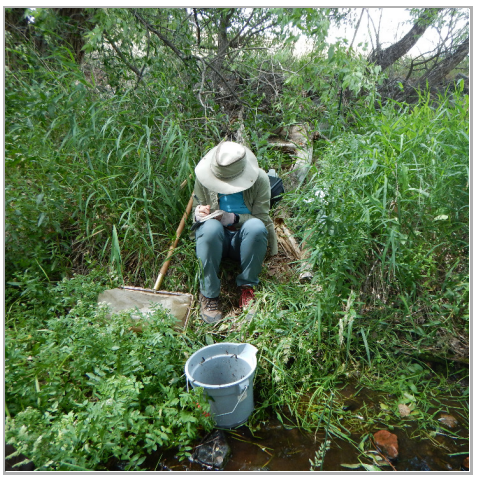

NOV 20, 2019

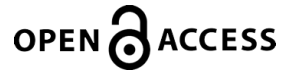

DOI:

dx.doi.org/10.17504/protocol s.io. $9 j 3 \mathrm{~h} 4 \mathrm{qn}$

Protocol Citation: Rebecca Hufft, Margo Paces, Meghan McGill, Richard A Levy 2019. Aquatic Monitoring Protocol for measuring and collecting ecological data. protocols.io https://dx.doi.org/10.17504/p rotocols.io.9j3h4qn

License: This is an open access protocol distributed under the terms of the Creative Commons Attribution License, which permits unrestricted use, distribution, and reproduction in any medium, provided the original author and source are credited

Protocol status: Working We use this protocol and it's working

Created: Nov 20, 2019

Last Modified: Nov 20, 2019

PROTOCOL integer ID: 30043

Keywords: water quality, stream, aquatic macroinvertebrate

\section{(3) Aquatic Monitoring Protocol for measuring and collecting ecological data}

\author{
Rebecca Hufft ${ }^{1}$, Margo Paces ${ }^{1}$, Meghan McGill ${ }^{1}, \quad$ Richard A Levy ${ }^{1}$ \\ ${ }^{1}$ Denver Botanic Gardens
}

Denver Botanic Gardens Research and Conservation

Tech. support email: richard.levy@botanicgardens.org

\section{Richard A Levy}

Denver Botanic Gardens

\section{ABSTRACT}

This protocol outlines the basic methods for measuring water quality and aquatic macroinvertebrate diversity. These measurements estimate the abundance and presence of aquatic macroinvertebrate species in an area, and link them to environmental conditions (plant community, water temperature and $\mathrm{pH}$, water nutrients, etc.) that may affect their distributions. Together, these data can reveal patterns in aquatic community or ecosystem processes. The stream measurements can be done independently but are usually paired with plant monitoring plots. When a plant monitoring plot is next to a creek or stream, the aquatic sampling occurs in the body of water nearest to the origin of the plant plot. See vegetation monitoring protocol (Hufft et al 2019) for more details.

\section{ATTACHMENTS \\ Aquatic Monitoring Protocol.pdf}




\section{MATERIALS}

- $25 \mathrm{~m}$ measuring tape

- Meter sticks

- Data sheets

- Clipboard

- Pen/pencils

-Water quality sampling bottles (see more information below)

- Water thermometer

- $\mathrm{pH}$ meter (check probe is not dry and stored in $\mathrm{pH} 4$ standard or storage solution)

- TDS meter

- DO meter (check sponge in cap is moist)

- EC meter

- Flow meter

- Kick net (500 $\mu \mathrm{m}$ mesh)

- D-frame net (500 $\mu \mathrm{m}$ mesh)

- Timer

- Macroinvertebrate collection jars

- Ethanol

- Sample labels

- Permanent Marker

- Squirt bottle of DI or RO water

- Squirt bottle of ethanol

- Rubber gloves

- Forceps

\section{Describing the Survey Location}

1 Before collecting ecological data, record information describing the survey location in a standardized way. Describe the location with the following physical location descriptors:

- Country

-1st political division (state)

- 2nd political division (county)

- Nearest population center, town, or village

- Directions and distance to the collection site from that town

- Any physical landmarks or landscape features that would help locate the site

- GPS coordinates, datum, and if possible, uncertainty

Record characteristics of the stream reach:

- Microhabitats present and in what proportion (riffle, pool, run, undercut bank)

- Water condition (murky, clear, foamy)

- Weather from previous day

- Water depth at origin (m)

- Surface water level at origin 


\section{Water Quality}

2 To measure water quality, we record abiotic characteristics of the water in situ and collect physical samples to send for external analysis.

Samples for lab analyses

1. Start at thalweg (deepest point) adjacent to transect origin.

2. Collect three water samples in official CDPHE bottles:

a. Nitrate/Nitrite $(250 \mathrm{ml})$

b. Total Nitrogen $(125 \mathrm{ml})$

c. E. coli $(125 \mathrm{ml})$

3. Fill each bottle to the max fill line.

4. Attach supplied CDPHE labels.

5. Fill out CDPHE Request for Analytical Services form. Each transect needs its own testing form.

6. Each water quality test will have its own specific bottle (3 per transect for E. coli, nitrate/nitrite, and total nitrogen)

a. Nutrient bottles contain an acid for preservation, so do not dump or spill bottles.

7. Take water samples at the thalweg origin, or if stream is too deep for wading, at the deepest point possible. Make sure to collect probe data and water samples at the same place and record this location on the datasheet.

8. Samples are TIME SENSITIVE. Samples must be dropped off within 8 hours of sampling. No sample drop-offs on Fridays.

\section{In-stream measurements}

3 1. Start at thalweg adjacent to vegetation transect origin. If thalweg is too deep to wade, take measurement at the deepest point possible and record this point on datasheet.

2. For each probe, make sure to not submerge probes past the point where the storage caps seal and swish the probe in water to remove air bubbles and allow reading to stabilize before recording.

3. Using the appropriate probes, collect the following data and record on data sheet:

a. Temperature $\left({ }^{\circ} \mathrm{C}\right)$ - Use $\mathrm{pH}$ probe's thermometer.

b. $\mathrm{pH}$

i. Probe should not be allowed to dry out. Store in $\mathrm{pH} 4$ standard (or storage solution if available).

ii. If probe does dry out, must soak in standard or storage solution for 1 hour before use.

c. Total Dissolved Solids (TDS)

d. Dissolved Oxygen (DO, mg/L)

i. If the probe has not been used in 7 days, requires 3 minutes to polarize. Turn probe on and wait 3 minutes before testing.

ii. Sponge in storage cap must always be moistened (but not soaked) with DI or RO water.

e. Electrical Conductivity (EC)

f. Flow

i. Beginning at thalweg at origin, find a section of reach with uniform bottom and flow.

ii. If thalweg is too deep to wade, take measurement at the deepest point possible at the origin 
and record location on datasheet.

iii. Plug cord into back of white unit, zero should appear on screen.

iv. To zero counter, switch position up.

v. To pause measurements, put switch in middle.

vi. To start measuring, put switch down.

vii. Use timer to measure flow for 60 seconds at $60 \%$ of stream depth.

viii. Once back in the office, to calculate surface velocity $(\mathrm{m} / \mathrm{s})$, convert the flowmeter readout using the following equation: $\mathrm{V}(\mathrm{c} / \mathrm{m})=(0.000854 \mathrm{C})+0.05$

g. Rinse all probes with RO water after use and before putting on cap to avoid contamination.

\section{Bank Measurements}

4 1. Total Bank Height: Distance from streambed at edge of bank to top of bank.

2. Surface to bank height: Distance from the water surface level to top of bank.

3. Distance to bank from Origin: Distance from the origin rebar to the edge of the adjacent stream bank.

4. If water is too deep at the thalweg to wade in, take measurements at the deepest point possible adjacent to the origin and record location on datasheet. This is especially important for stream reaches with dams.

\section{Soil Moisture}

5 1. At the origin of the vegetation transect, lay a $10 \mathrm{~m}$ transect perpendicular to the transect starting $(0 \mathrm{~m})$ at the stream bank.

2. For every meter, starting at meter 0 , insert the soil moisture meter (on whichever side of the tape it penetrates most easily) to a depth of 8 inches $(20 \mathrm{~cm})$ (entire length of metal piece).

3. Record the percent volumetric soil moisture that appears on the screen.

a. If soil is very wet, meter may take several minutes to stabilize.

b. If point is under water, record " $W$ " for moisture level.

c. If soil is too rocky to insert the full length of the probe, record "Too Rocky" on the data sheet, or " $\mathrm{TH}$ " if the soil is too hard.

d. If soil is past saturation point, - - - - will appear on screen. Record "- - - -" on the data sheet.

\section{Aquatic Macroinvertebrate Sampling}

6 To measure water quality, we also collect biotic characteristics of the aquatic community by sampling the abundance and diversity of aquatic macroinvertebrates. Below we present instructions that function for our existing work.

1. Since the water is moving when we sample, we use the kicknetting method.

2. Start at thalweg at $20 \mathrm{~m}$ mark downstream from origin. Start downstream and move upstream toward origin (See Fig. 1)

3. Conduct kicknetting for 1 minute every 5 meters, for 5 sampling bouts moving upstream.

4. 5 sampling bouts should be conducted for each transects. 
a. However, samples should be $5 \mathrm{~m}$ apart, so if large parts of the stream are dry, only take as many samples as the stream allows.

5. At each sampling bout,

a. Disturb area $1 \mathrm{~m} 2$ upstream of net, using heel or toe to dislodge the upper layer of cobble/gravel and scrape underlying bed.

b. Pick up larger substrate and rub by hand to remove attached organisms.

c. If the water is slow moving, use your hands or feet to push what has been kicked up into the net.

d. Exclude specimens clinging to the outside of nets.

6. Place contents of net into the mesh bucket.

a. Rinse outside of net to move sediment and specimens inside the net to one corner.

b. Flip net inside out in bucket and rinse down outside of net with more water to wash all contents into bucket.

c. To avoid contamination of the sample, do not pour water into the side of the net with the specimens. Only pour water on the outside of the net.

d. Continue adding contents of net into mesh bucket for the length of the transect.

7. Scoop specimens into $1 \mathrm{~L}$ plastic rectangular Nalgene sampling jar with hand. It may be necessary to place the mesh bucket in the stream and swirl to get specimens to one side.

a. Release any fish, amphibians, reptiles, or crayfish back into stream, but record their presence on the data sheet.

8. Fill jar with no more than $50 \%$ of sample material from the stream. Use more than one jar per sample if necessary.

a. Add ethanol to the bottles to create a 50:50 sample to ethanol ratio.

b. In 2018 we used an average of 2-3 bottles per sample site (max 5 at TSP and dammed sites) and roughly $2.5750 \mathrm{ml}$ of ethanol per day.

9. Pick out and scrape off larger rocks in the bucket to remove any macroinvertebrates clinging to them. Smaller gravel can be added to bottle.

10. Properly label each bottle using a marker that is not alcohol-soluble. Check naming conventions file to make sure samples are labelled consistently from year to year.

11. Follow the instructions below for proper storage and sample drop off for identification.

12. Backwash the net with stream water before collecting samples from the next site.

\section{Water Sample Processing}

7 Water analyses are conducted by the Colorado Department of Public Health and Environment (CDPHE). Samples are time sensitive. Please coordinate a time to drop off samples ahead of time. 